\title{
Weight Status and Perception of Colorectal Cancer Risk
}

\author{
Heather Bittner Fagan, MD, MPH, FAAFP, Randa Sifri, MD, Richard Wender, MD, \\ Elena Schumacher, RD, and James F. Reed III, PhD
}

Background: Obesity increases the risk of many cancers including colorectal cancer (CRC).

Methods: This is secondary data analysis of the 2010 National Health Interview Survey data. A total of 9360 obese and overweight participants, aged 50 to 80 years, were analyzed according to their perception of their personal cancer risk.

Results: Having a perception of increased risk for cancer was associated with higher CRC screening rates. However, when compared with their normal-weight counterparts, overweight and obese individuals did not perceive themselves as being at an increased risk for cancer in general or for CRC specifically. Subgroup analysis revealed one notable exception. Obese black women appeared to recognize themselves as being at higher risk for CRC.

Conclusions: Most obese and overweight individuals fail to recognize their increased cancer risk. Individuals who perceive themselves as being at increased risk for cancer, especially CRC, are more likely to have undergone CRC screening. Unfortunately, obese and overweight individuals do not seem to recognize the increased cancer risk conferred by their body weight. Education is needed so that obese and overweight individuals are aware that their excess body weight is a risk factor for cancer. (J Am Board Fam Med 2012;25:792-797.)

Keywords: Cancer Risk, Colon/Colorectal Cancer Screening, Obesity, Weight Status

An estimated $68 \%$ of US adults are either obese or overweight. ${ }^{1}$ Obesity is associated with an increased risk for several types of cancers, including colorectal cancer (CRC). Obesity is second only to tobacco as a modifiable risk factor for cancer. ${ }^{2}$ It has been estimated that $>41,000$ cancer cases per year are due to obesity. ${ }^{3}$ The relative risk of CRC for both men and women increases as body mass

\footnotetext{
This article was externally peer reviewed.

Submitted 19 January 2012; revised 8 August 2012; accepted 13 August 2012.

From the Department of Family and Community Medicine, Christiana Care Health System, Wilmington, DE (HBF, JFR); the Department of Family and Community Medicine, Jefferson Medical College, Philadelphia (RS, RW); the Helen F. Graham Cancer Center; and Academic Affairs, Christiana Care Health System, Newark, DE (ES).

Funding: This work was supported by the Cancer Control Career Development Award 115834-CCCDA-08-107-01CCCDA from the American Cancer Society.

Conflict of interest: none declared.

Corresponding author: Heather Bittner Fagan, MD, MPH, FAAFP, Department of Family and Community Medicine, Christiana Care Health System, 1400 North Washington Street, Wilmington, DE 19801 (E-mail: hbittner-fagan@christianacare.org).
}

index (BMI) increases. Relative risk for CRC in men is 1 in 20 when BMI 25.0 to $29.9 \mathrm{~kg} / \mathrm{m}^{2}, 1.47$ when $\mathrm{BMI}$ is 30.0 to $34.9 \mathrm{~kg} / \mathrm{m}^{2}$, and 1.84 when $\mathrm{BMI}$ is 35.0 to $39.9 \mathrm{~kg} / \mathrm{m}^{2}$. Relative risk for CRC in women is 1 in 10 when BMI 25.0 to $29.9 \mathrm{~kg} / \mathrm{m}^{2}$, 1.33 when BMI is 30.0 to $34.9 \mathrm{~kg} / \mathrm{m}^{2}, 1.36$ when $\mathrm{BMI}$ is 35.0 to $39.9 \mathrm{~kg} / \mathrm{m}^{2}$, and 1.46 when $\mathrm{BMI}$ is $\geq 40.0 \mathrm{~kg} / \mathrm{m}^{2} .4$

Thus, there is increasing interest in promoting healthy weight through healthy eating and physical activity as a cancer prevention strategy. In addition, there may be a reason for increased diligence in cancer screening in the overweight and obese population. If individuals at higher weight recognize themselves as being at higher risk for cancer, they will, arguably, be more likely to screen for CRC or other cancers. Many models of behavior change suppose that perception of risk is a motivator of action related to preventive behavior, including behavior related to cancer prevention. ${ }^{5-7}$ However, many individuals may not recognize obesity as an important and modifiable risk factor for cancer. ${ }^{8}$ 
The purpose of this study is to determine if overweight and obese individuals recognize a higher personal risk for cancer in general and for CRC specifically. Prior research indicates that men and women perceive their weight differently ${ }^{9}$; likewise, nonwhite minorities also view their weight differently than whites. ${ }^{10,11}$ Therefore, subgroup analysis is completed to see if cancer risk perception is different in women or blacks.

\section{Methods}

This was a cross-sectional study analyzing data from the 2010 National Health Interview Survey, a nationally representative survey of the civilian noninstitutionalized population of the United States. The National Health Interview Survey is a cross-sectional household interview survey. The sampling plan follows a multistage area probability design that permits the representative sampling of households and noninstitutional group quarters (eg, college dormitories) and oversamples of blacks, Hispanics, and Asians. This complex survey design allows for population estimates of the United States. ${ }^{12}$

\section{Participants}

The National Health Interview Survey respondents in this study were individuals aged $\geq 50$ years old because CRC screening would be recommended for these individuals according to the American Cancer Society. ${ }^{13}$ Individuals $>80$ years of age were excluded, acknowledging that there is some controversy regarding the age at which CRC screening should be discontinued. Within this participant group, the association between perception of cancer risk and a particular behavior, CRC screening, could be analyzed, therefore demonstrating an association between perception of risk and an action to mitigate that risk.

\section{Variables}

\section{Perception of Increased Cancer Risk}

Perception of cancer risk was self-reported as "more than the average person," "approximately the same as the average person," or "less than the average person" for both cancer in general and for CRC specifically. Individuals who answered "more than the average person" were classified as having a perception of increased cancer risk; individuals who answered "approximately the same as the average person" or "less than the average person" were classified as not having a perception of increased risk.

\section{Weight Status}

Obesity was defined according to BMI, which was calculated as weight in kilograms divided by the square of height in meters. BMI was categorized as underweight $\left(<18.5 \mathrm{~kg} / \mathrm{m}^{2}\right)$, normal weight (18.5$\left.24.9 \mathrm{~kg} / \mathrm{m}^{2}\right)$, overweight $\left(25-29.9 \mathrm{~kg} / \mathrm{m}^{2}\right)$, and obese $\left(\geq 30 \mathrm{~kg} / \mathrm{m}^{2}\right) .{ }^{14}$ Due to small sample size, underweight individuals were excluded. ${ }^{15}$

\section{CRC Screening}

We examined the self-reported variables related to endoscopy, stool blood testing, and test date. The outcome variable of overall CRC screening status was defined as up to date in individuals who had one of the following screening tests: colonoscopy within the last 10 years, sigmoidoscopy in the last 5 years, or fecal occult blood test within the last year. ${ }^{13}$ To be included, an individual must have had complete answers (both test and date) to at least one of the aforementioned screening test questions.

\section{Covariates}

We examined the potential confounding variables of age (50-59, 60-69, 70-79 years); education ( $<12$ years, high school graduate, some college, college graduate); marital status (married, unmarried); race/ethnicity (Hispanic, non-Hispanic white, non-Hispanic black); health status (fair/poor, excellent/good); income $(<\$ 20,000$, $\$ 20,000-\$ 25,000, \$ 35,000-\$ 55,000, \$ 55,000-\$ 75,000$, $\$ 75,000+$ ); insurance status (yes/no); office visits in the last year (none, one, 2-5, $\geq 6$ ); regular source of medical care (yes/no); smoking status (current, former, never); physician recommendation (yes/no); alcohol use (none, light to moderate, heavy); number of comorbidities (zero, one, 2-3, 4-5, $\geq 6$ ); family history defined as any primary relative with a cancer diagnosis (yes/no); personal history of cancer (yes/no); and physician recommendation (yes/no).

\section{Results}

Selection criteria for this study included the following: age between 50 and 79 and nonmissing data for BMI, colorectal screening, perceived risk of cancer, and perceived risk of colon cancer. Using this selection criteria, there were 9360 eligible participants with "nonmissing" data. We assumed that 
Table 1. Demographic Characteristics of Participants According to Weight Status (n = 9360)

\begin{tabular}{|c|c|c|c|}
\hline $50-59$ & $48.3 \%$ & $48.2 \%$ & $52.0 \%$ \\
\hline $60-69$ & $28.5 \%$ & $31.6 \%$ & $31.6 \%$ \\
\hline $70-79$ & $23.2 \%$ & $20.2 \%$ & $16.4 \%$ \\
\hline Less than 12 years & $14.2 \%$ & $15.8 \%$ & $18.0 \%$ \\
\hline High school graduate & $27.6 \%$ & $30.1 \%$ & $32.2 \%$ \\
\hline Some college & $23.1 \%$ & $25.7 \%$ & $29.3 \%$ \\
\hline College or more & $35.1 \%$ & $28.4 \%$ & $20.5 \%$ \\
\hline \multicolumn{4}{|l|}{ Marital status } \\
\hline Non-Hispanic white & $86.8 \%$ & $81.6 \%$ & $80.3 \%$ \\
\hline Non-Hispanic black & $7.3 \%$ & $9.8 \%$ & $11.4 \%$ \\
\hline \multicolumn{4}{|l|}{ Reported health status } \\
\hline Excellent/good & $84.5 \%$ & $83.8 \%$ & $74.5 \%$ \\
\hline Fair/poor & $15.5 \%$ & $16.2 \%$ & $25.5 \%$ \\
\hline \multicolumn{4}{|l|}{ Household income } \\
\hline$<\$ 20,000$ & $27.2 \%$ & $25.0 \%$ & $26.9 \%$ \\
\hline$\$ 20,000-35,000$ & $18.3 \%$ & $22.4 \%$ & $21.4 \%$ \\
\hline$\$ 35,000-55,000$ & $22.8 \%$ & $22.7 \%$ & $25.3 \%$ \\
\hline$\$ 55,000-75,000$ & $14.0 \%$ & $14.7 \%$ & $13.7 \%$ \\
\hline $2-5$ & $43.0 \%$ & $43.4 \%$ & $42.3 \%$ \\
\hline $6+$ & $29.2 \%$ & $29.9 \%$ & $39.0 \%$ \\
\hline Regular source of medical care & $90.3 \%$ & $91.5 \%$ & $93.2 \%$ \\
\hline \multicolumn{4}{|l|}{ Smoking status } \\
\hline Never & $50.1 \%$ & $47.6 \%$ & $50.9 \%$ \\
\hline Former & $29.0 \%$ & $36.5 \%$ & $35.3 \%$ \\
\hline Current & $20.9 \%$ & $15.9 \%$ & $13.8 \%$ \\
\hline \multicolumn{4}{|l|}{ Alcohol use } \\
\hline None & $40.2 \%$ & $40.2 \%$ & $48.4 \%$ \\
\hline Light to moderate & $53.7 \%$ & $55.2 \%$ & $48.3 \%$ \\
\hline Heavy & $6.1 \%$ & $4.6 \%$ & $3.3 \%$ \\
\hline \multicolumn{4}{|l|}{ Comorbidities } \\
\hline 0 & $35.0 \%$ & $28.3 \%$ & $16.7 \%$ \\
\hline 1 & $31.3 \%$ & $30.6 \%$ & $24.5 \%$ \\
\hline $2-3$ & $27.2 \%$ & $31.8 \%$ & $42.2 \%$ \\
\hline $4-5$ & $5.3 \%$ & $7.8 \%$ & $13.9 \%$ \\
\hline \multirow[t]{2}{*}{$\geq 6$} & $1.2 \%$ & $1.5 \%$ & $2.7 \%$ \\
\hline & & & Continued \\
\hline
\end{tabular}




\begin{tabular}{|c|c|c|c|}
\hline & \multicolumn{3}{|c|}{ Weight Status $(\mathrm{n}=9360)$} \\
\hline & Normal $(\mathrm{n}=2787)$ & Overweight $(\mathrm{n}=3600)$ & Obese $(\mathrm{n}=2973)$ \\
\hline \multicolumn{4}{|c|}{ Family history of cancer } \\
\hline Yes & $84.4 \%$ & $82.6 \%$ & $83.9 \%$ \\
\hline No & $15.6 \%$ & $17.4 \%$ & $16.1 \%$ \\
\hline \multicolumn{4}{|c|}{ Personal history of cancer } \\
\hline Yes & $14.0 \%$ & $13.4 \%$ & $13.6 \%$ \\
\hline No & $86.0 \%$ & $86.6 \%$ & $86.4 \%$ \\
\hline \multicolumn{4}{|c|}{ Physician recommendation } \\
\hline Yes & $54.6 \%$ & $54.1 \%$ & $55.3 \%$ \\
\hline No & $45.4 \%$ & $45.9 \%$ & $44.7 \%$ \\
\hline
\end{tabular}

missing data were missing at random and therefore would not affect the subsequent analyses.

Table 1 demonstrates the demographics of our population according to weight status and according to several known predictors of CRC screening. In the adjusted analysis (not shown), only family history and smoking status were significant predictors for perception of cancer risk. These variables were incorporated in the adjusted analysis of the outcome CRC screening examined in Table 2. Table 2 examines the outcome of CRC screening according to perception of risk. Having a perception of increased cancer risk in general is associated with increased CRC screening (OR, 1.66; 95\% CI, 1.47-1.87). Likewise, having a perception of increased cancer risk, specifically for CRC, is strongly associated with increased CRC screening (OR, 2.71; 95\% CI, 2.33-3.15). Table 3 shows perception of cancer risk according to weight status. There is no association between weight status, being overweight or obese, with having a perception of increased cancer risk in general or for CRC specifically. Table 4 stratifies the outcome of perception of increased cancer risk according to race and sex. With the exception of obese black females, there are no significant associations between weight status and perception of increased cancer risk. We did not include those who self-identify as Hispanic in Table 4 due to a small sample size.

\section{Discussion}

Our work demonstrates that perception of cancer risk is associated with higher CRC screening rates, supporting the theoretical link between perceived risk and an individual's likelihood to take action to prevent cancer. However, overweight and obese individuals, in this study, do not perceive themselves to be at higher risk for cancer in general nor for CRC specifically. This finding may illustrate an important gap in public health knowledge. If individuals recognize increased weight as a modifiable risk factor for cancer, they may be motivated to make lifestyle changes or at least be more diligent regarding screening. Obese and overweight individuals who fail to recognize an increase in their own personal risk for cancer may be less likely to engage in cancer prevention behavior and less likely to be positively influenced by cancer prevention messages.

Of interest, Finkelstein et $\mathrm{al}^{16}$ found that obese persons do perceive their life expectancy to be

Table 2. Perception of Increased Cancer Risk Is Associated with CRC Screening (n= 8334)

\begin{tabular}{lccl}
\hline Perception of Increased Risk for Cancer & $\mathrm{n}$ & Up-to-Date for CRC Screening & OR (95\% CI) \\
\hline Yes & 1221 & $58.2 \%(711)$ & $1.66(1.47-1.87)$ \\
No & 8179 & $45.7 \%(3470)$ & $1.00^{*}$ \\
Perception of Increased Risk for CRC & $\mathrm{n}$ & Up-to-Date for CRC Screening & OR (95\% CI) \\
Yes & 878 & $69.0 \%(606)$ & $2.71(2.33-3.15)$ \\
No & 8522 & $45.1 \%(3845)$ & $1.00^{*}$ \\
\hline
\end{tabular}

${ }^{*}$ Reference.

CRC, colorectal cancer; OR, odds ratio; CI, confidence interval. 
Table 3. Perception of Cancer Risk According to Weight Status $(\mathrm{n}=9360)$

\begin{tabular}{lcc}
\hline Weight Status & $\begin{array}{c}\text { Perception of } \\
\text { Increased Risk for } \\
\text { Cancer in General }\end{array}$ & $\begin{array}{c}\text { Perception of } \\
\text { Increased Risk } \\
\text { of CRC }\end{array}$ \\
\hline Normal $(\mathrm{n}=353)$ & $1.00^{*}$ & $1.00^{*}$ \\
Overweight $(\mathrm{n}=455)$ & $1.00(0.85-1.18)$ & $1.03(0.85-1.25)$ \\
Obese $(\mathrm{n}=413)$ & $1.05(0.88-1.25)$ & $1.15(0.94-1.40)$ \\
\hline
\end{tabular}

$>$ *Reference.

CRC, colorectal cancer.

shorter because of their weight status. They also found that obese persons regard themselves at a higher risk for cancer than normal-weight individuals. However, this study did not control for family history or smoking history. We found these factors to be significant predictors of risk perception as did Honda and Neugut in 2004. ${ }^{17}$ This is an important distinction because weight is modifiable unlike family history or a history of smoking.

These data show one notable exception. Obese black women do appear to see themselves as being at higher risk for CRC. This is somewhat consistent with the literature, which shows that women were more likely than men to see their weight as a health risk. ${ }^{10}$ Likewise, the literature supports that obese individuals are more likely to see their weight as a problem compared with overweight individu- als. ${ }^{18}$ However, it is unclear why black and not white women perceive this risk when, ironically, some data indicate that the link between obesity and cancer risk is weakest in black women. ${ }^{19}$ Perhaps black women perceive a higher CRC risk because they more often see the diagnosis made in family members. Kim et $\mathrm{al}^{20}$ found that family history was a predictor of perceived risk for CRC among a group of diverse women. The opposite trend, although not statistically significant, is seen in black men, in which obese black men see themselves as at decreased risk for cancer compared with nonobese black men. Black men have the highest incidence of colon cancer irrespective of weight status with 62.0 of 100,000 black men diagnosed in $2007 .^{21}$ This is especially concerning given that an increased risk of colon cancer with obesity has been shown more consistently in men than women. ${ }^{22-24}$ Unfortunately, small sample size precluded our ability to examine the subgroup of Hispanic individuals.

Public health education needs to incorporate cancer risk into education programs for weight loss and obesity prevention and more research needs to be done on cancer risk perception in obese individuals. Educating the public of their increased cancer risk with obesity should be a priority, because obese persons may not fully comprehend this health risk. Current attempts at lowering obesity are not working. If fear of a cancer diagnosis is motivational,

Table 4. Association between Perception of Cancer Risk and Weight Status According to Sex and Race $(\mathrm{n}=\mathbf{9 3 6 0}$, Subdivided into Groups)

\begin{tabular}{llcc}
\hline & & $\begin{array}{c}\text { Increased Perception of Risk for } \\
\text { Any Cancer; OR (95\% CI) }\end{array}$ & $\begin{array}{c}\text { Increased Perception of Risk } \\
\text { for CRC; OR (95\% CI) }\end{array}$ \\
\hline White males & Normal $(\mathrm{n}=786)$ & 1.00 (reference) & 1.00 (reference) \\
& Overweight $(\mathrm{n}=1480)$ & $1.05(0.76-1.45)$ & $1.02(0.70-1.50)$ \\
& Obese $(\mathrm{n}=893)$ & $1.19(0.84-1.68)$ & $1.48(1.0-2.19)$ \\
Black males & Normal $(\mathrm{n}=149)$ & 1.00 (reference) & 1.00 (reference) \\
& Overweight $(\mathrm{n}=218)$ & $0.83(0.40-1.72)$ & $0.91(0.40-2.07)$ \\
& Obese $(\mathrm{n}=141)$ & $0.73(0.33-1.63)$ & $0.37(0.12-1.11)$ \\
White females & Normal $(\mathrm{n}=1476)$ & 1.00 (reference) & 1.00 (reference) \\
& Overweight $(\mathrm{n}=1224)$ & $1.16(0.91-1.48)$ & $1.23(0.93-1.61)$ \\
& Obese $(\mathrm{n}=1271)$ & $1.14(0.90-1.44)$ & $1.07(0.81-1.42)$ \\
Black females & Normal $(\mathrm{n}=136)$ & 1.00 (reference) & 1.00 (reference) \\
& Overweight $(\mathrm{n}=238)$ & $1.31(0.58-2.99)$ & $2.72(0.74-10.02)$ \\
& Obese $(\mathrm{n}=322)$ & $1.19(0.54-2.64)$ & $3.90(1.12-13.52)$ \\
\hline
\end{tabular}

*Those who self-identify as Hispanic are not included in the data set. CRC, colorectal cancer; OR, odds ratio; CI, confidence interval. 
then by making more people aware of the increased cancer risk with obesity may encourage behavior changes conducive to decreasing cancer risk.

\section{References}

1. Flegal KM, Carroll MD, Ogden CL, Curtin LR. Prevalence and trends in obesity among US adults, 1999-2008. JAMA. 2010;303:235-41.

2. American Cancer Society. Cancer facts and figures 2011. Available at: www.cancer.org/research/ cancerfactsfigures/cancerfactsfigures/cancer-factsfigures-2011. Updated 2011. Accessed August 1, 2011.

3. Polednak AP. Trends in incidence rates for obesityassociated cancers in the US. Cancer Detect Prev 2003;27:415-21.

4. Calle EE, Rodriguez C, Walker-Thurmond K, Thu MJ. Overweight, obesity and mortality from cancer in a prospectively studied cohort of US adults. N Engl J Med 2003;348:1625-38.

5. Janz NK, Champion VL, Strecher VJ. The health belief model. In: Glanz K, Rimer BK, Lewis FM, editors. Health behavior and health education: Theory, research, and practice. 3rd ed. San Francisco, CA: Jossey-Bass; 2002, p. 45-66.

6. Myers RE. Self regulation and decision-making about cancer screening. In: Cameron LD, Leventhal $\mathrm{H}$, editors. The self-regulation of health and illness behaviour. London, UK, and New York, NY: Routledge; 2003. p. 297-313.

7. Myers RE. Decision counseling in cancer prevention and control. Health Psychol 2005;24(suppl):S71-7.

8. Cameron M, Scully M, Herd N, Jamsen K, Hill D, Wakefield M. The role of overweight and obesity in perceived risk factors for cancer: implications for education. J Cancer Educ 2010;25:506-11.

9. Gregory CO, Blanck HM, Gillespie C, Maynard LM, Serdula MK. Perceived health risk of excess body weight among overweight and obese men and women: differences by sex. Prev Med. 2008;47: 46-52.

10. Anderson LA, Eyler AA, Galuska DA, Brown DR, Brownson RC. Relationship of satisfaction with body size and trying to lose weight in a national survey of overweight and obese women aged 40 and older, United States. Prev Med 2002;35:390-6.

11. Fitzgibbon ML, Blackman LR, Avellone ME. The relationship between body image discrepancy and body mass index across ethnic groups. Obes Res 2000;8:582-9.
12. Centers for Disease Control and Prevention (CDC). National Health Interview Survey (NHIS)-description. Available at: www.cdc.gov/nchs/nhis.htm. Updated 2011. Accessed August 1, 2011.

13. American Cancer Society. Colorectal cancer facts and figures special edition 2005. Atlanta (GA): American Cancer Society; 2005. p. 1-19.

14. Centers for Disease Control and Prevention (CDC). Use of colorectal cancer tests-united states, 2002, 2004, and 2006. MMWR Morb Mortal Wkly Rep. 2008;57:253-8.

15. Centers for Disease Control and Prevention (CDC). Prevalence and trends data-adults who are current smokers. Available at: http://wonder.cdc.gov/brfss. html. Updated 2007. Accessed April 9, 2009.

16. Finkelstein EA, Brown DS, Evans WD. Do obese persons comprehend their personal health risks? Am J Health Behav 2008;32:508-16.

17. Honda K, Neugut AI. Associations between perceived cancer risk and established risk factors in a national community sample. Cancer Detect Prev 2004;28:1-7.

18. Bittner-Fagan H, Diamond J, Myers R, Gill JM. Perception, intention, and action in adolescent obesity. J Am Board Fam Med 2008;21:555-61.

19. National Cancer Institute. Fact sheet 3.7 obesity and cancer. Available at: www.cancer.org/cancertopics/ factsheet/risk/obesity. Updated 2004. Accessed December 7, 2011.

20. Kim SE, Perez-Stable EJ, Wong S, Gregorich S, Sawaya GF, Walsh JME, Kaplan CP. Association between cancer risk perception and screening behavior among diverse women. Arch Intern Med 2008; 168:728-34.

21. Centers for Disease Control and Prevention (CDC). Colorectal (colon) cancer incidence rates. Available at: www.cdc.gov/Features/dsColorectalCancer/. Updated April 4, 2011. Accessed June 18, 2012.

22. Caan BJ, Coates AO, Slattery ML, Potter JD, Quesenberry CP Jr, Edwards SM. Body size and the risk of colon cancer in a large case-control study. Int J Obes Relat Metab Disord. 1998;22:178-84.

23. Giacosa A, Franceschi S, La Vecchia C, Favero A, Andreatta R. Energy intake, overweight, physical exercise and colorectal cancer risk. Eur J Cancer Prev 1999;8(suppl 1):S53-60.

24. Murphy TK, Calle EE, Rodriguez C, Kahn HS, Thun MJ. Body mass index and colon cancer mortality in a large prospective study. Am J Epidemiol 2000;152:847-54. 